\title{
Technology demonstration of a novel seabed resident event-driven profiling system
}

\author{
Antonio Mascarenhas*, Nitin Dabholkar, Jayu Narvekar, Shivanand Prabhudesai, \\ Siddharth Ghatkar, Sadaf Ansari, Pramod Maurya, Elgar Desa, Anand Lokapure, \\ Surekha Nagvekar, Gajanan Navelkar, R. Madhan, Fernando Vijayan, Vidish Shetye, \\ Llewellyn Fernandes, Sanjeev Afzulpurkar and T. Suresh
}

The seabed resident event-driven profiling system (SREP) was deployed in the northeastern Arabian Sea for winter convention studies. SREP is an autonomous profiling system consisting of two parts: a stationary seabed unit and a positively buoyant tethered profiling unit (profiler). It offers a novel and optimized approach to profiling in coastal waters from close to seabed (14.63 $\mathrm{m}$ above seabed) to the sea surface. The seabed unit houses an underwater winch system, underwater acoustic modem, pressure sensor, low-power electronics, batteries and divinylcell hydraulic crush point foam for subsea applications. The profiler houses a suite of oceanographic sensors: conductivitytemperature-depth, DO, chlorophyll, PAR, underwater acoustic modem, low-power electronics, batteries and divinylcell hydraulic crush point foam for subsea applications. The underwater winch system on the seabed unit spools out and spools in the profiler throughout the water column. Data acquisition on the profiler is done during ascending. The profiler ascends gradually in the water column at an average velocity of $20 \mathrm{~cm} / \mathrm{s}$. The seabed unit and the profiling unit communicate using a pair of underwater acoustic modems operating at 18-34 kHz. SREP was developed to obtain time-series water column measurements of coastal waters during the summer monsoon season (June-September) when the sea wave and wind conditions are extreme, thus making it difficult to deploy profiling packages from the ship. A description of SREP and observations made during the field deployment are presented in this article.

Keywords: Coastal waters, profiling system, seabed unit, technology demonstration, winter convention studies.

THE west coast of India experiences upwelling during monsoon season. Nutrient-rich upwelled water fertilizes the upper oxygenated coastal waters resulting in increased biological productivity. Long-term continuous profiling of the coastal waters is essential to unravel such monsoon-driven changes in the Arabian Sea. The seabed resident event driven profiling system (SREP) developed at the Marine Instrumentation Division of the National Institute of Oceanography, Goa, India is a water column profiling system that can be deployed in coastal waters using an oceanographic mooring. The underwater winch system on the seabed unit spools out the tethered buoyant profiler gradually through the water column until it

Antonio Mascarenhas, Nitin Dabholkar, Jayu Narvekar, Shivanand Prabhudesai, Siddharth Ghatkar, Sadaf Ansari, Pramod Maurya, Elgar Desa, Anand Lokapure, Surekha Nagvekar, Gajanan Navelkar, R. Madhan, Fernando Vijayan, Vidish Shetye, Llewellyn Fernandes, Sanjeev Afzulpurkar and T. Suresh are in the National Institute of Oceanography, Dona Paula, Goa 403 004, India.

*For correspondence. (e-mail: antonio@nio.org) reaches the sea surface. Throughout the spool-out phase, the profiler acquires data and at fixed time intervals transmits the most recently acquired data packet (via the acoustic channel) to the sea-bed unit for safekeeping. After remaining on the surface for a short duration of $30 \mathrm{sec}$, the underwater winch system spools in the profiler. The unique features of SREP are: acoustic communication between the seabed and profiling units ${ }^{1}$, battery power saving using low-power electronics and sleepwake-up modules, data redundancy on the seabed unit in the event of accidental loss of the profiling unit and timetriggered and forced (user command) profiling modes. There are other autonomous profilers which are capable of measuring upper-layer water column similar to the SREP, viz. HOMER (HOMing Environmental Recorder) ${ }^{2}$, CAPABLE (The Coastal Autonomous Profiler And Boundary Layer system $)^{3}$, SeaCycler ${ }^{4}$ and uprising microstructure profiler ${ }^{5}$. A different class of profilers like the wire walker, uses the ocean wave energy to move a buoyant profiler down a wire suspended from a surface 
float and uses only buoyancy to surface up ${ }^{6}$. Here we describe the SREP and present the field deployment results.

\section{The seabed resident event-driven profiling system}

Figure 1 shows the SREP configuration. The function of the winch system on the seabed unit is to spool out and spool in the positively buoyant profiler. During the spoolout phase, the profiler ascends the water column by virtue of its buoyancy $(\sim 10 \mathrm{kgf})$. This buoyancy is provided by divinylcell hydraulic crush point (HCP 50) floats for subsea applications. These floats are rated for $300 \mathrm{~m}$ water depth and 50 bar crushing pressure limit. They have a density of $250 \mathrm{~kg} / \mathrm{m}^{3}$ and can be easily machined. The profiler is tethered to the seabed unit using a nonconductive $3 \mathrm{~mm}$ diameter mono filament kevlar rope with maximum breaking strength of $300 \mathrm{~kg}$. Table 1 provides the main specifications of SREP. The conductivity

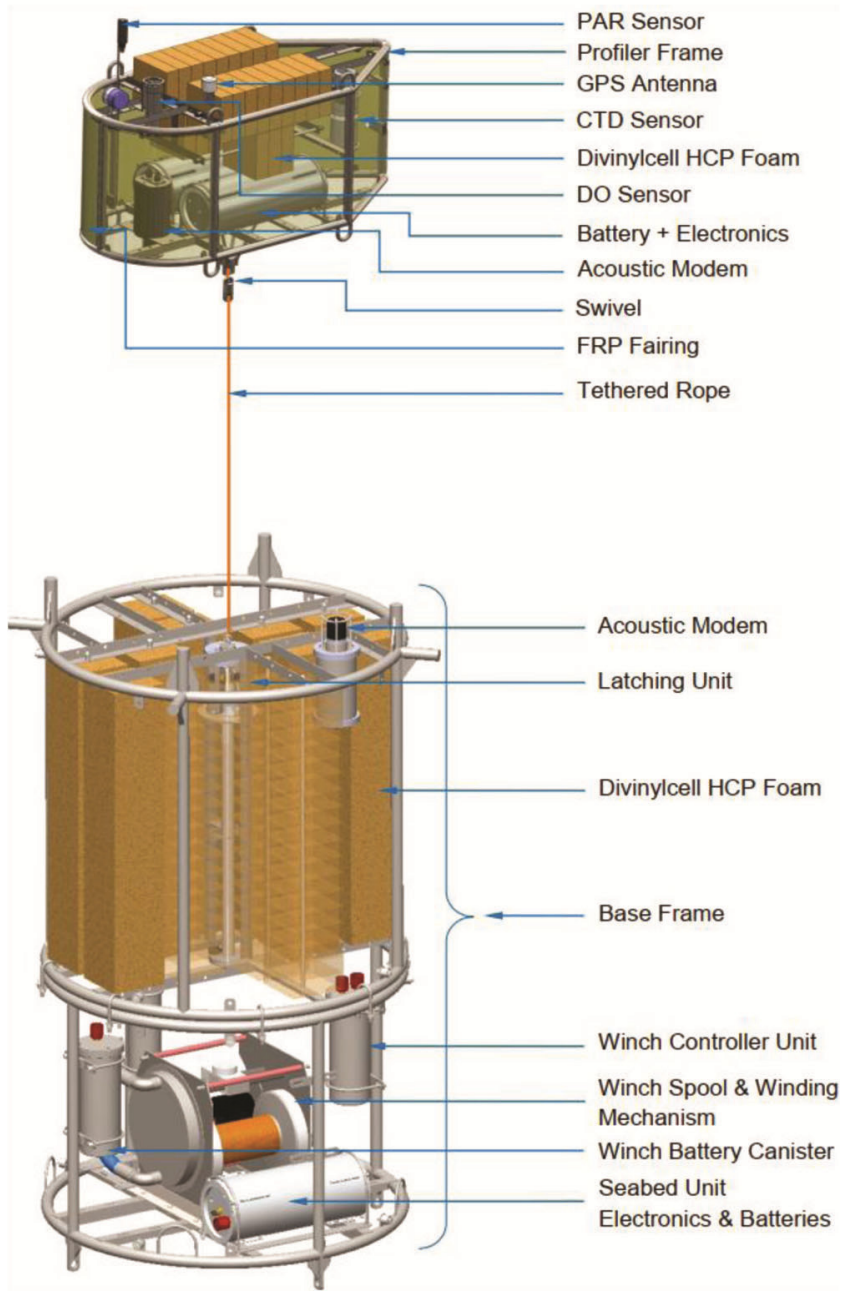

Figure 1. Three-dimensional drawing of the SREP showing the profiler latched to the seabed unit and oriented upwards as would be the case before the start of profile. temperature depth (CTD) sensor is non-pumped, model CTD-NV (Citadel); sampled at $4 \mathrm{~Hz}$. The dissolved oxygen (DO) sensor is RINKO2 (JFE ALEC) sampled at $1 \mathrm{~Hz}$. Chlorophyll and turbidity sensor is FLNTUS (Wetlabs); sampled at $\sim 4 \mathrm{~Hz}$. Photosynthetically active radiation (PAR) sensor is PAR-SER (Satlantic); sampled at $4 \mathrm{~Hz}$. At a pre-designated profiling time (timed profile), the SREP wakes up, powers on the sensors, unlatches the tethered profiler and initiates a profile. The winch spools out the profiler gradually in the water column at an average speed of $20 \mathrm{~cm} / \mathrm{s}$. At every $4 \mathrm{sec}$ interval the profiler transmits a most recent acquired data packet to the seabed unit using the underwater acoustic modem for data redundancy. The profiler rises to the water surface due to its positive buoyancy, with the tether remaining taut throughout, until the profiler breaks the sea surface. When the profiler is on the surface, the slackness in the tether is detected by the tensioner and the winch stops spooling out. Additionally, the profiler commands the seabed unit to stop spooling out when it is on the surface. These are the safety measures to avoid creeping of the tether. After a brief stay of $30 \mathrm{sec}$ on surface the winch starts spooling in the profiler which is switched to a low-power mode with no data acquisition while descending, until it is latched to the seabed unit waiting for the next time profile to commence. Power saving is achieved using ultra-low power consumption electronics (PIC 18F97J94). Apart from the timed profiles, SREP can be commanded to execute a forced profile using a compatible ship-based ultra short base line-cum-acoustic modem (USBL). The USBL when configured in the promiscuous mode is able to capture the instant message communication between the seabed unit and the profiler acoustic modems during profiling, which is useful for monitoring the performance of SREP.

\section{Sea deployment}

During the period 5 February to 4 March 2018, SREP was deployed at a location (latitude: $20^{\circ} 18.183 \mathrm{~N}$, longitude: $69^{\circ} 25.161 \mathrm{E}$ ) in the northeastern Arabian Sea (Figure 2) off the Indian coast of Gujarat for winter convention studies using National Institute of Oceanography (NIO)'s research vessel $R V$ Sindhu Sankalp (cruise SSK115). The deployment location was selected in the region close to the $200 \mathrm{~m}$ depth contour line with a gradual change in depth up to $205 \mathrm{~m}$, i.e. 0.5 nautical miles west of the $200 \mathrm{~m}$ depth contour. A standard mooring configuration consisting of anchor weight, acoustic release, hard ball floats and the necessary mechanical hardware (chains, shackles and swivel) was used for deployment.

On 5 February 2018, the mooring components were assembled and pre-checks were carried out on SREP (seabed unit and profiler). A gantry test for the seabed unit was performed using the A-frame pulley of the ship 
Table 1. SREP specifications

\begin{tabular}{|c|c|}
\hline \multicolumn{2}{|l|}{ Seabed unit } \\
\hline SS304 frame dimensions height and diameter & Height $=1.6 \mathrm{~m}$; diameter $=1.0 \mathrm{~m}$ \\
\hline Weight in air & $\sim 228 \mathrm{~kg}$ \\
\hline Net buoyancy in water & $\sim 80 \mathrm{kgf}$ \\
\hline Tested depth & $200 \mathrm{~m}$ \\
\hline Endurance (estimated) & 100 days; with 2 profiles/day up to $200 \mathrm{~m}$ \\
\hline Power source (winch motor assembly) & Lithium sulfuryl chloride primary cells $(2880 \mathrm{Wh} / 2 \times 24 \mathrm{~V} / 60 \mathrm{Ah}) *$ \\
\hline Power source (winch controller) & Lithium bromine chloride primary cells ( $240 \mathrm{Wh})$ \\
\hline Power source (acoustic modem, sensors, electronics) & Lithium ion polymer cells $(864 \mathrm{Wh} / 24 \mathrm{~V})$ \\
\hline Total average power & 3.5 Whr/day during profile; $3.9 \mathrm{Whr} /$ day during sleep mode \\
\hline Communication & $18-34 \mathrm{kHz}, 1 \mathrm{kbaud}$ (acoustic modem) \\
\hline Electronics (microcontroller) & PIC18F97J94 \\
\hline Sensors & Pressure sensor Keller 36XW \\
\hline \multicolumn{2}{|l|}{ Profiling unit } \\
\hline SS304 frame dimensions: height, length and width & Height $=0.5 \mathrm{~m}$; length $=1.1 \mathrm{~m} ;$ width $=0.4 \mathrm{~m}$ hydrofoil shape \\
\hline Weight in air & $\sim 66 \mathrm{~kg} \quad$ \\
\hline Net buoyancy in water & $\sim 10 \mathrm{kgf}$ \\
\hline Tested depth & $200 \mathrm{~m}$ \\
\hline Endurance (estimated) & 100 days with 2 profiles/day up to $200 \mathrm{~m}$ \\
\hline Power source (acoustic modem, sensors, electronics) & Lithium ion polymer cells $(1296 \mathrm{Wh} / 24 \mathrm{~V})$ \\
\hline Total average power & $7.8 \mathrm{Wh} /$ day during profile; $3.89 \mathrm{Wh} /$ day during sleep mode \\
\hline Communication & $18-34 \mathrm{kHz}, 1 \mathrm{kbaud}$ acoustic modem \\
\hline Electronics (microcontroller) & PIC18F97J94 \\
\hline Sensors & $\begin{array}{l}\text { Chlorophyll, turbidity, conductivity-temperature-depth, dissolved oxygen, } \\
\text { photosynthetically active radiation }\end{array}$ \\
\hline Minimum distance of sensors from seabed & $14.63 \mathrm{~m}$ \\
\hline
\end{tabular}

*Standard battery set consists of two banks of $24 \mathrm{~V} / 60 \mathrm{Ah}$ connected in parallel. Additional battery bank can be installed to achieve the estimated endurance.

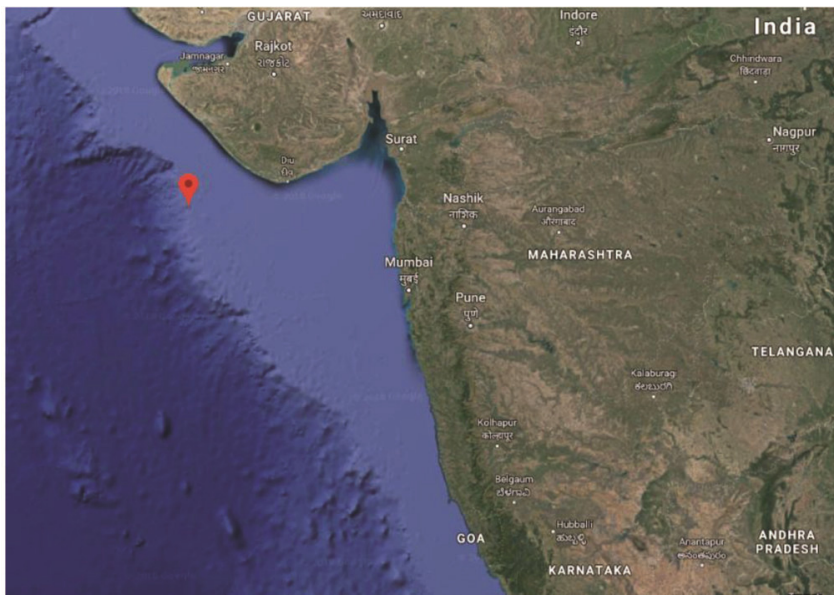

Figure 2. SREP deployment location (latitude: $20^{\circ} 18.183 \mathrm{~N}$, longitude: $\left.69^{\circ} 25.161 \mathrm{E}\right)$.

with a $10 \mathrm{~kg}$ weight simulating the buoyancy of the profiler. SREP was deployed at 15:27 h.

The deployment operation was completed in about $15 \mathrm{~min}$. After a gap of $1 \mathrm{~h}$, a forced profile command was issued to SREP using the ship-based USBL and acknowledgement of profile initiation was received. Another forced profile command was issued later in the evening. Per-programmed timed profiles designated at 02:00 h and $14: 00 \mathrm{~h}$ were initiated by SREP from 6 February 2018.
After a month of deployment, a cruise (no. SSK117) was undertaken from 2 to 7 March 2018 to observe the performance and retrieve the SREP system. On the morning of 5 March 2018, the ship was positioned at the SREP drop point location and ship echo sounders were switched-off to eliminate possible interference with the $12.0 \mathrm{kHz}$ acoustic release deck unit transducer. A ranging command was executed using the acoustic release deck unit and the measured slant range of the SREP acoustic release was $284 \mathrm{~m}$. Post-verification, a release command was issued at 08:15 h. SREP surfaced in the estimated time of 2 min $33 \mathrm{sec}$.

The ship was manoeuvred to position the SREP off the starboard bow with the wind on the starboard side. The SREP was grabbed from the ship's bow using a grapnel hook. The profiler was manually lifted on the front deck and disconnected. The seabed unit was lifted using a 0.6 tonne crane followed by the mooring components (hardball floats and acoustic release). The retrieval operation was complete at 09:00 $\mathrm{h}$.

In all, 54 timed profiles were executed. One timed profile $(02: 00 \mathrm{~h}, 11$ February 2018) failed to execute. During the period from $18(02: 00 \mathrm{~h})$ to 22 February 2018 $(14: 00 \mathrm{~h})$, the profiler continuously surfaced up. Figure 3 shows the velocity of the profiler while ascending. The velocity varied from 10 to $30 \mathrm{~cm} / \mathrm{s}$ and the average velocity of the profiler was $20 \mathrm{~cm} / \mathrm{s}$. We used a second-order lowpass butterworts filter, with cut-off frequency at $0.1 \mathrm{rad} / \mathrm{s}$. The filter was implemented with zero phase 
distortion. All the profiles did not sample up to the surface because of the drag force on the profiler and the presence of underwater currents, due to which the profiler encountered profile termination condition (mission timeout: $980 \mathrm{sec}$ or maximum payout length: $250 \mathrm{~m}$ ).

\section{Observations}

It is known that during winter (November to February), the northern Arabian Sea cools due to radiative heat loss as well as heat loss due to enhanced evaporation under the dry continental trade winds that blow from the Asian land mass towards the ocean ${ }^{7}$. Evaporation not only lowers the surface temperature, but also increases the salinity of the surface waters. Thus, the resultant cooling combined with the increased salinity enhances the density of the surface waters. This densification of surface waters

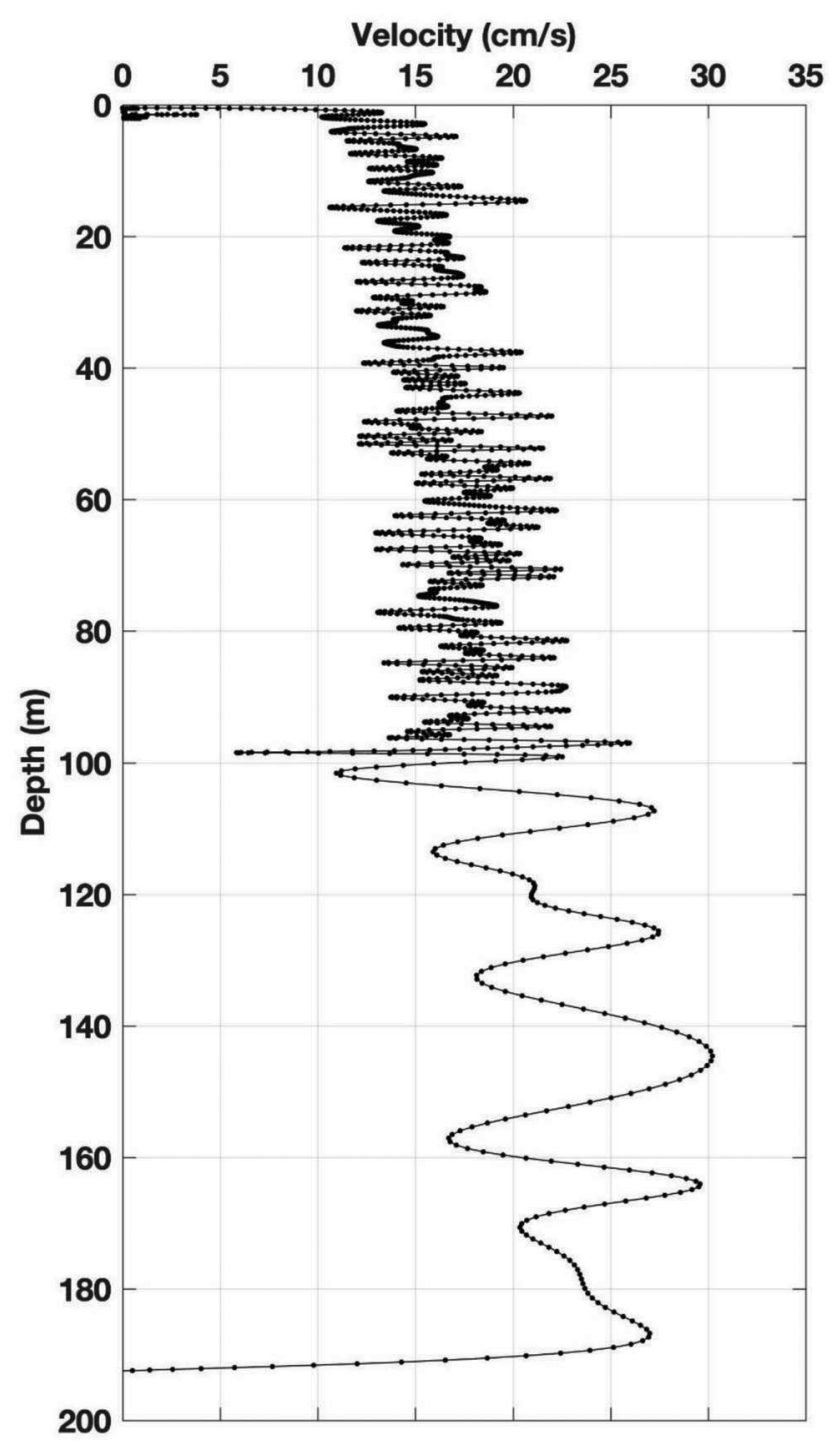

Figure 3. Profiler velocity (date: 12 February 2018, time: 14:00 h). kick-starts the convective mixing, thereby deepening the oceanic mixed layer. In this process of deepening of mixed layer, the subsurface waters from the upper nutracline/thermocline are brought into the upper water column thus fertilizing the euphotic zone. This process initiates the rapid photosynthesis by phytoplankton, which eventually leads to the phytoplankton bloom. Though the mechanism of winter bloom is somewhat understood in detail, what is not known is the time evolution of convection and the intra-seasonal variability of the phytoplankton bloom. In this context, SREP was deployed in the northern Arabian Sea during February to March 2018 to capture the signatures of winter cooling and convection, and associated winter phytoplankton bloom.

The vertical distribution of temperature during February and March 2018 in the northern Arabian Sea showed warm temperatures of $26^{\circ} \mathrm{C}$ in the upper $50 \mathrm{~m}$ of the water column during the first week of February (Figure $4)$. The upper water column temperature was further reduced to $25^{\circ} \mathrm{C}$ till the end of February 2018. This indicates that winter cooling was more intensified during 9 to 28 February 2018. In the first week of March 2018, a warming in the upper ocean was noticed with increase in temperature by $1{ }^{\circ} \mathrm{C}$. In the subsurface levels, colder waters with temperature of $17^{\circ}-18^{\circ} \mathrm{C}$ were seen entraining towards shallower depths during the active spell of winter cooling. This indicates that there was strong convective mixing during 10-24 February 2018. Isothermal layer showed a shoaling trend from 100 to $20 \mathrm{~m}$ during 5-28 February 2018.

The mixed layer depth (MLD) was calculated based on the temperature criteria, i.e. $1^{\circ} \mathrm{C}$ drop from sea surface temperature. The MLD showed $100 \mathrm{~m}$ variability during the observation period from 5 February to 5 March 2018. During 5 to 22 February, mixed layer was deep and was on an average about $90 \mathrm{~m}$. The maximum value of MLD was 120 m during 6 and 15 February 2018, which clearly indicates that winter cooling and convection were active till 22 February 2018 in the study region. After 22 February 2018, a sudden shoaling in MLD was observed and it shoaled to $30 \mathrm{~m}$ (Figure 5). Again during the first week of March 2018, MLD showed a gradual deepening trend. A total of 54 profiles were used to understand the upper water column structure, out of which 50 profiles sampled the water column from 195 to $25 \mathrm{~m}$. Since MLD during the period of observation varied from 30 to $120 \mathrm{~m}$, the four profiles which did not sample from the surface to $25 \mathrm{~m}$ would not impact the determination of mixed layer. A total of 33 profiles were sampled from near surface to $195 \mathrm{~m}$. These data were used to understand the time evolution of winter cooling in the northern Arabian Sea. The present data can be used for the above studies, as MLD which is the indicator of winter convection is greater than $30 \mathrm{~m}$. 


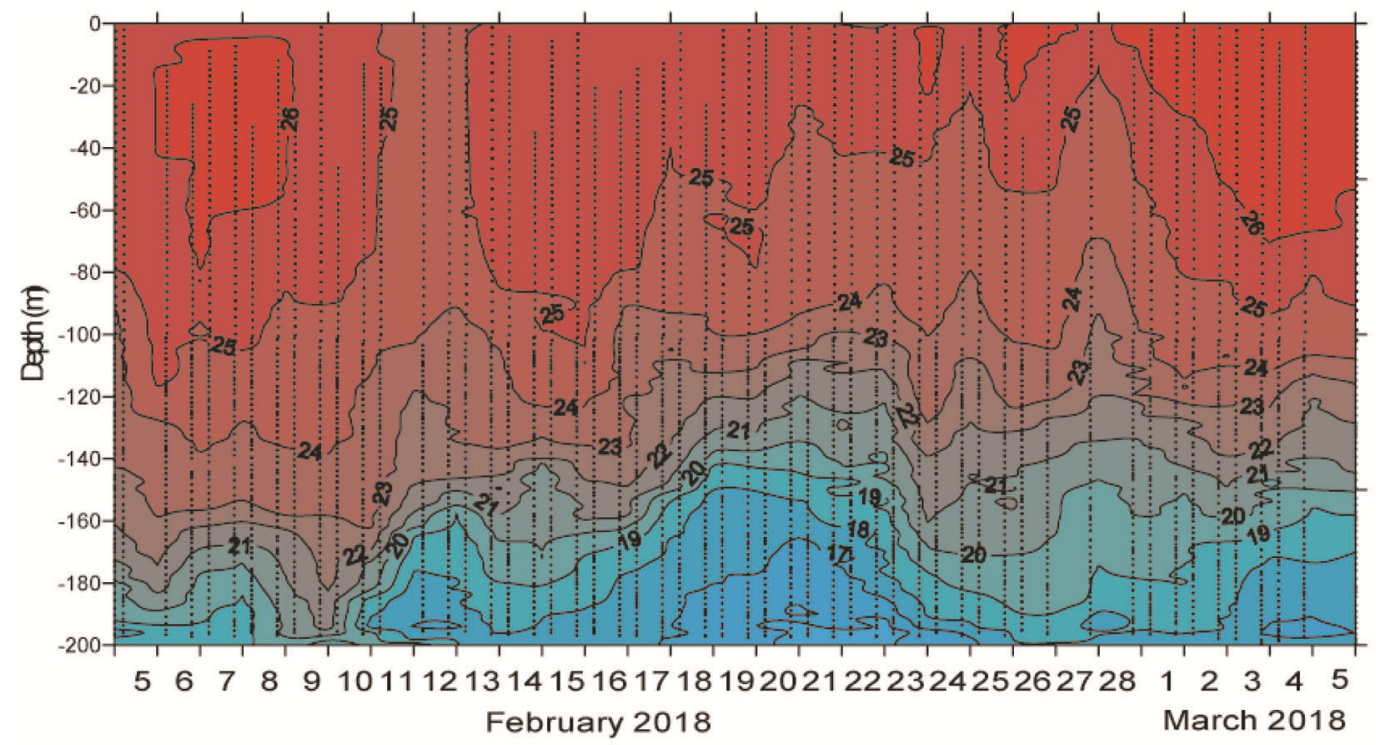

Figure 4. Time evolution of temperature captured by SREP.

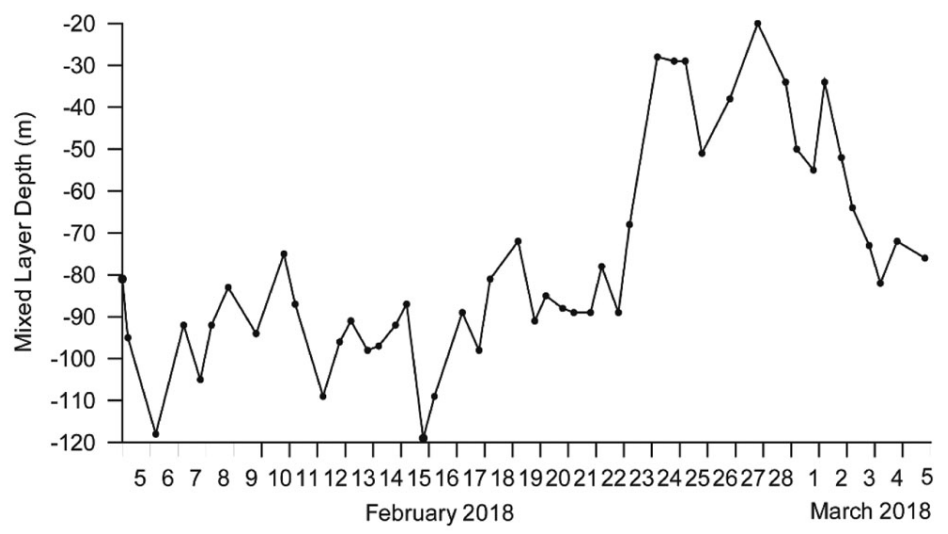

Figure 5. Mixed layer depth (MLD) variability during 5 February to 5 March 2018 in the northern Arabian Sea based on SREP data.

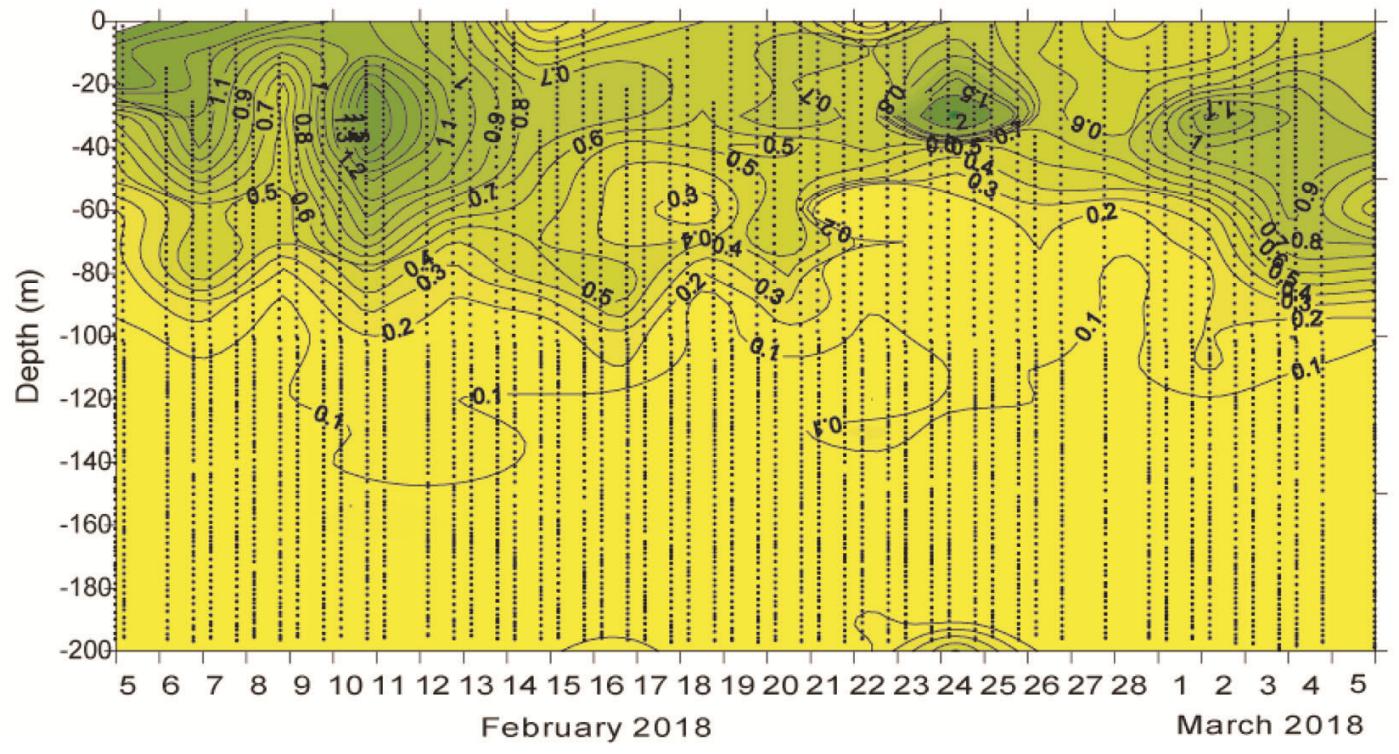

Figure 6. Time evolution of chlorophyll captured by SREP. 


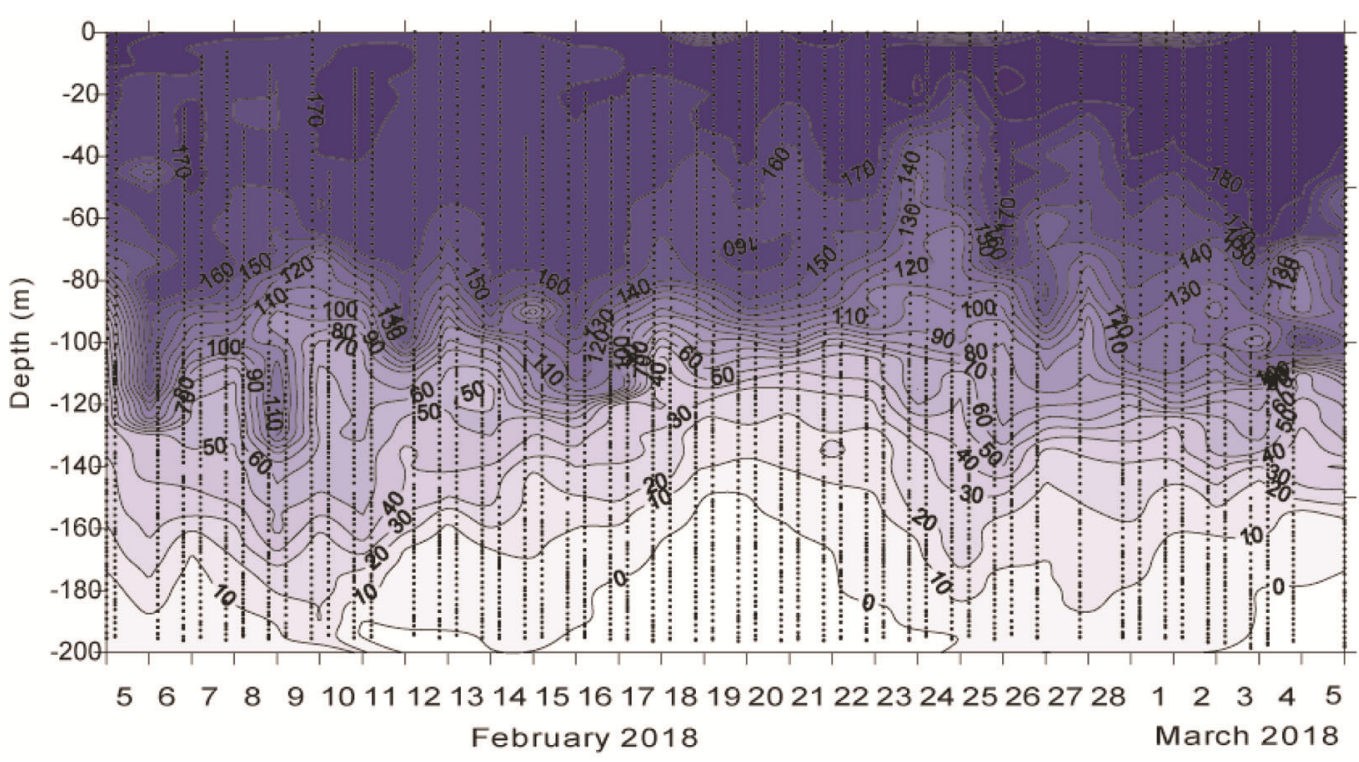

Figure 7. Time evolution of dissolved oxygen captured by SREP.

The chlorophyll variability in the upper $200 \mathrm{~m}$ clearly shows that the phytoplankton productivity occurs in the upper $100 \mathrm{~m}$ in the northern Arabian Sea during winter. The upper $80 \mathrm{~m}$ of water column showed high levels of chlorophyll concentration throughout February. The maximum chlorophyll of $2 \mathrm{mg} / \mathrm{m}^{3}$ was observed during 24 and 25 February 2018 (Figure 6). The turbidity values of the water column throughout the deployment varied between 1 and 3 NTU, and would not affect the chlorophyll measurements.

The vertical distribution of DO showed a well-oxygenated upper $40 \mathrm{~m}$ of water column, with values exceeding $170 \mu \mathrm{mol} / \mathrm{kg}$ from 5 to 24 February 2018. Thereafter, the surface waters showed an increasing DO concentration up to $180 \mu \mathrm{mol} / \mathrm{kg}$ (Figure 7). The evolution of DO showed a progressive shoaling of oxycline with time, for example, the $140 \mu \mathrm{mol} / \mathrm{kg}$ isopleth shoaled from $110 \mathrm{~m}$ in the first week to $40 \mathrm{~m}$ towards the last week of February. The most striking feature of the distribution is the presence of suboxic waters below $160 \mathrm{~m}$ during the entire measuring period. However, from 11 to 25 February 2018, anoxic waters were seen below $180 \mathrm{~m}$. A second episode of anoxic waters was noticed towards the end of the measurement period below $180 \mathrm{~m}$. These suboxic and anoxic waters are important in the context of denitrification and also the ecosystem response. Thus SREP was able to precisely capture the episodic occurrences of anoxic conditions.

\section{Conclusion}

The SREP was successfully deployed and retrieved using research vessel $R$. $V$. Sindhu Sankalp. The month long deployment proved the sea worthiness of SREP system.
The SREP captured the signatures of winter cooling and convection and the associated winter phytoplankton bloom.

1. Mascarenhas, A. et al., A seabed resident event driven profiling system for use in coastal waters. Indian patent filed on 19 January 2015 (application No. 158/DEL/2015).

2. Inall, M., Meldrum, D., Provost, P. G., Mercer, D. J. L., Griffiths, C., Peppe, O. C. and Vassie, I., HOMER: early results from a novel seabed-resident water column profiler. In OCEANS'05, IEEE Oceanic Engineering Society. Conference Proceedings, 2005, vols 1 and 2, pp. 1252-1255.

3. Barnard, A. H. et al., The coastal autonomous profiler and boundary layer system (CAPABLE). In OCEANS'10, IEEE Marine Technology Society, Conference Proceedings, 2010, pp. 1-7.

4. Send, U. et al., SeaCycler: a moored open-ocean profiling system for the upper ocean in extended self-contained deployments. J. Atmos. Ocean. Technol., 2013, 30(7), 1555-1565.

5. Prandke, H. and Stips, A., Microstructure profiler to study mixing and turbulent transport processes. In OCEANS'98, IEEE Oceanic Engineering Society. Conference Proceedings (Cat. No. 98CH36259), 1998, vol. 1, pp. 179-183.

6. Pinkel, R. et al., The wirewalker: a vertically profiling instrument carrier powered by ocean waves. J. Atmosp. Ocean. Technol., 2011, 28(3), 426-435.

7. Prasanna Kumar, S. and Prasad, T. G., Winter cooling in the northern Arabian Sea. Curr. Sci., 1996, 71, 834-841.

ACKNOWLEDGEMENTS. We thank the Director, CSIR-National Institute of Oceanography (NIO), Goa, members of the mooring group: Narayan Satelkar, Sadashiv Khalap, Mithun Gaonkar, Prakash Tari, and the Research Vessel Management Group of NIO: Shashikant Velip and Kuldeep Kumar. We also thank the Director General, Council of Scientific and Industrial Research (CSIR), New Delhi for funding the project. This is NIO contribution 6469 .

Received 24 May 2019; revised accepted 11 September 2020

doi: $10.18520 / \mathrm{cs} / \mathrm{v} 120 / \mathrm{i} 4 / 622-627$ 